\title{
TOWARDS THE NEW ENERGY STORAGE SYSTEM FOR CONVENTIONAL CARS
}

\author{
Saša Sladić ${ }^{*}$ - Alen Poljak - Neven Bulić
}

Faculty of Engineering, University of Rijeka, Vukovarska 58, Rijeka, Croatia

\begin{tabular}{l}
\hline ARTICLE INFO \\
\hline Article history: \\
Received: 03.08 .2017$. \\
Received in revised form: 12.10 .2017$. \\
Accepted: 13.10 .2017$. \\
\hline Keywords: \\
Electric energy storage system (ESS) \\
Conventional car modeling \\
Battery modeling \\
Supercapacitors \\
Supercapacitor modeling \\
Electric machine modelling
\end{tabular}

DOI: https://doi.org/10.30765/er.38.3.2

\begin{abstract}
:
Lead-acid batteries are widely used in conventional cars. This electric energy storage system (ESS) has to be capable to store enough energy for cranking the conventional car after the weeks without additional charging. After the start of internal combustion engine (ICE) of conventional car synchronous machine usually called alternator start to generate electrical energy. Electric current supplied in this way should be rectified and stored in lead-acid battery for the next start-up. In this article a model of whole process was developed and simulated. Particularly, a supercapacitors were compared with lead-acid batteries and other battery types in sense of mass, reliability and other parameters. Results were confirmed by measurement on conventional car. Furthermore, possibility of replacement of lead-acid batteries with supercapacitors was analyzed.
\end{abstract}

Furthermore, Lead-acid batteries are also suitable for stationary (e.g. photovoltaic) applications since they are cost effective and durable [1]. Consequently, Budde-Meiwes et. al. have concluded that Lead-acid batteries are indispensable energy storage for conventional cars; however this type of batteries have to be improved [2]. First option is to use more advanced materials for electrodes in frame of Leadacid technology [3], [4], [5], [6]. In this case a cycle life cycle of battery is prolonged usually by carbon or titanium-dioxide doping of electrode. In other hand, supercapacitors or EDCLs (Electric Double Layer Capacitors) are modern technology which could replace lead-acid batteries since in this way a successful cranking could be performed. This technology is still developing [7], [8], [9]. New materials as nanotubes and graphene are under focus [10]. Recently, nanomaterials based on carbon found

\footnotetext{
* Corresponding author. Tel.: 0038551651 440;

E-mail address: sladics@ riteh.hr
} 
their applications in supercapacitor electrodes [10]. However, it is hard to perform more than one cranking with supercapacitors. Third option is combined electric energy storage which consists of Lead-acid battery and supercapacitors. In this way performances of lead-acid batteries could be improved via connections with supercapacitors or other storage systems [11], [12], [13], [14], [15]. Less cost effective solution is the replacement of Leadacid batteries with other batteries. In spite the fact this solution is possible, less than $1 \%$ of conventional cars has alternate solution [16]. In this way an observation from [2] has been confirmed.

\section{Model of conventional car}

Conventional car is a nonlinear system made from numerous subsystems which involve different level of nonlinearity. Internal combustion engine (ICE) takes central place, supported by two electric machines and few power converters (usually rectifiers). This approach appeared to be complex, especially considered the ICE engine. Different nonlinear functions appear for compression torque, viscous friction torque and Coulomb friction torque [17] where a diesel engine was modeled.

In this paper a gasoline internal combustion engine has been modeled by simple DC circuit with thyristor and mechanical switch. In this circuit, thyristor simulates start-up of the ICE machine, and operates uniformly after the initial signal. Constant engine speed after cranking was modeled by constant current of equivalent circuit.

\subsection{Modeling of Internal combustion engine}

Modeling an ICE is complex [17]. But it could be approximated by nonlinear electric circuit (Figure 1).

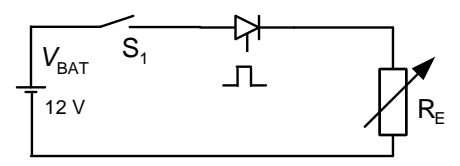

\section{Figure 1. Simplified equivalent circuit of ICE engine.}

In spite of positive battery voltage, current will not flow until both switch $\mathrm{S}_{1}$ (contact key) and thyristor are both on. That means ICE engine will not turn on until engine speed of $200 \mathrm{rpms}$ is not achieved. If the current is lower (analogy with the engine speed) thyristor will not conduct. This effect is analogous to holding current of thyristor. After the thyristor starts conducting ICE engine generates constant torque for the electricity generation via AC machine. By position of the gas pedal (or value of resistor $R_{\mathrm{E}}$ ) different engine speed (or current) could be achieved. Turning of the engine could be achieved by turning off the switch $S_{1}$ or by increase of the load $R_{\mathrm{E}}$. After the successful cranking ICE machine develops constant torque for alternator action.

\subsection{Electric starter model}

Serie wound DC motor has been often used for cranking of ICE motor. However, variants with magnets could be founded, also. Produced torque could be calculated by product of magnetic field and rotor current, generally:

$$
M=k_{1} I_{A}^{2}
$$

for the machine with the current dependent (series wound) magnetic field or

$$
M=k_{2} I_{A}
$$

in the case when the permanent magnets were used, relation between the developed torque $M$ of the DC motor and armature (rotor) current $I_{\mathrm{A}}$. Both constants $k_{1}$ and $k_{2}$ depends on machine construction. Also a combination of both approaches $(2,3)$ is possible. In spite the fact that DC motor does not represent reliable solution it has been used frequently because of its cost effectiveness.

\subsection{Alternator model}

In conventional cars, a synchronous machine with regulated magnetic field (electromagnet) on rotor has been used. In order to maintain constant induced voltage during the different operating conditions (different vehicle speed) a regulating circuit has to be aided to rotor circuit of synchronous machine. In this paper a model with permanent magnets has been used. In this way a conditions during cranking were simulated without high speed analysis.

\subsection{Battery model}

Batteries are highly nonlinear electrochemical devices which could be hardly simulated in details. However, there are a few different battery models including single resistance and single capacitance 
and two resistances and two capacitances (two pair $R C$ model) [17]. These two models are enough for basic comparison of batteries and supercapacitors. However, more advanced modeling for the purpose of cycle life and other long term parameters has to be performed practically by precise measurements only. According to model from Figure 2 a voltage equation could be written:

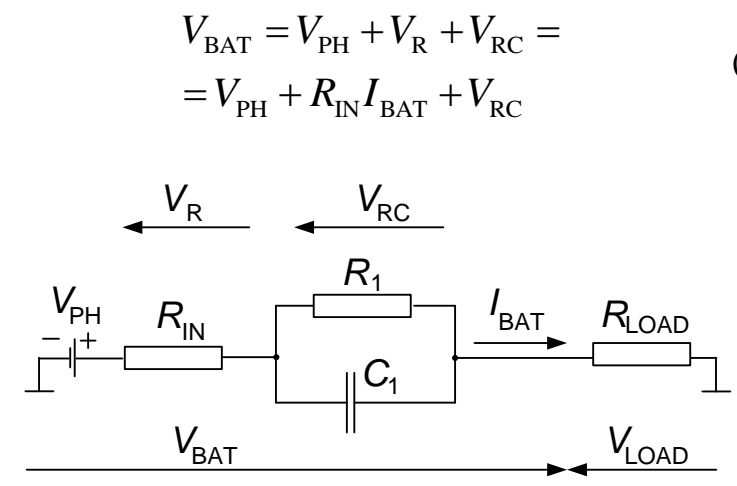

Figure 2. Simplified schematic of Lead-acid battery connected to the load.

\subsection{Supercapacitor model}

Supercapacitors have simpler models than batteries [9], [17], [18] both in the sense of charging and discharging and in the sense of the lifetime (SOL) determination. Basically, supercapacitors could be modeled by serially connected capacitance and resistance. For a short term tests a self-discharging resistance could be neglected:

$$
V_{\mathrm{SC}}=V_{\mathrm{PH}}+V_{\mathrm{R}}=V_{\mathrm{PH}}+R_{\mathrm{IN}} I_{\mathrm{SC}}
$$

Model from Figure 3 was taken into account for simulation of cranking which lasts up to two seconds. However, during the testing of supercapacitors it has been noted that supercapacitors tend to discharge after few hours. So, for the longer tests additional resistance should be added to the Figure 2 . Furthermore, in sense of balancing of serially connected supercapacitors they should be connected parallel with additional resistors or other components for voltage balancing in order to prevent the unequal voltage on particular supercapacitors [19]. Elements for the simulation were taken from the datasheets, and tests performed in [20], [21], or directly from measurement on commercial car.

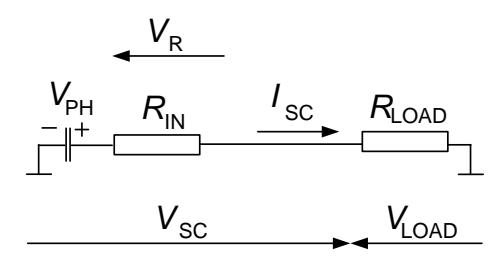

Figure 3. Simplified schematic of supercapacitor connected to the load.

\subsection{Simulation results and measurements for different storage systems}

In order to simulate cranking of the conventional car with different storage systems a simplified model of conventional car has been developed (Figure. 4). This model simulate cranking of conventional car on parking. Conveniently, a practical results in order to confirm simulation results were also taken under such conditions.

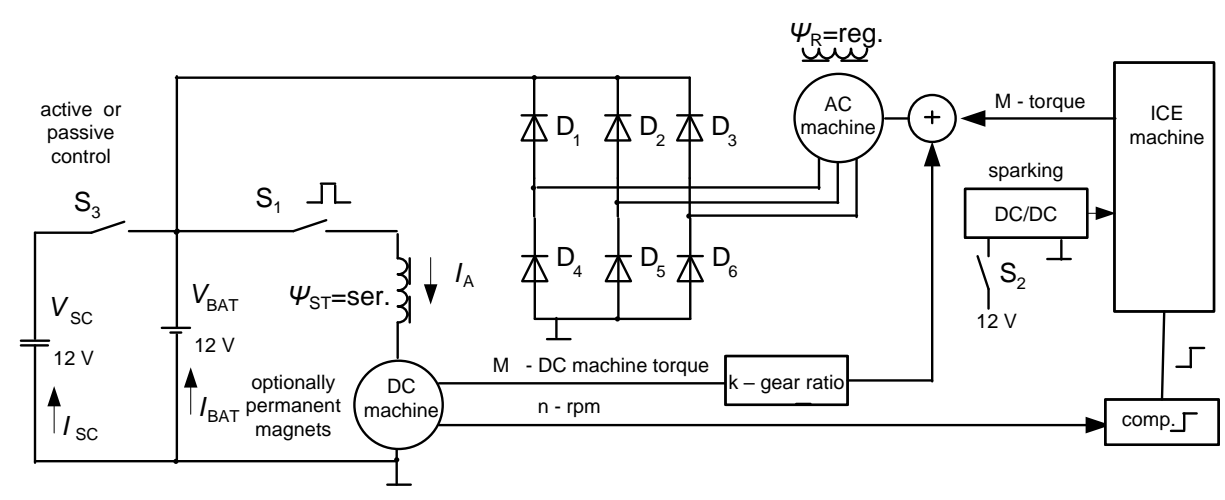

Figure 4. Simplified schematic of conventional car which enables simulation of different energy storage systems during cranking. 


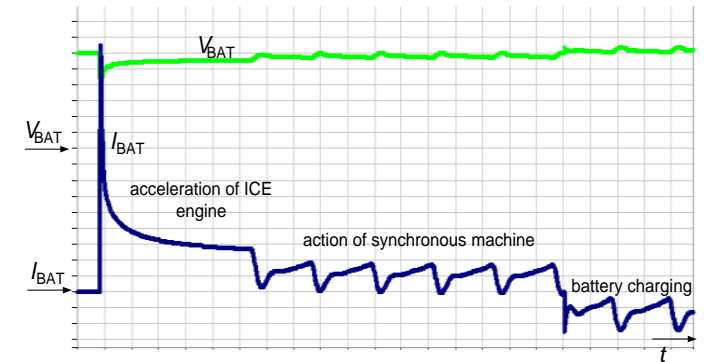

a)

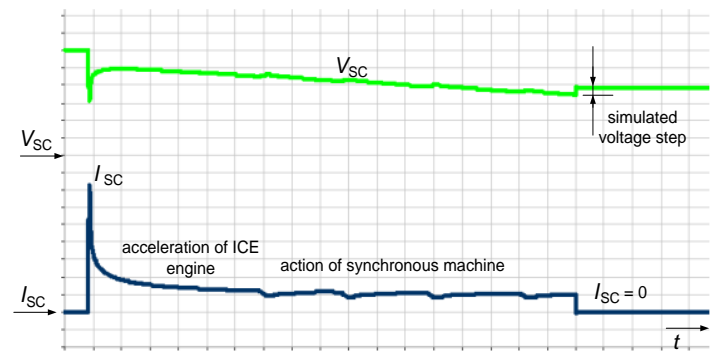

b)

Figure 5. Simulated waveforms of DC bus voltage and current of the energy storage system during cranking; a) lead-acid battery successful cranking, b) supercapacitor unsuccessful cranking (25 A/div., 2 V/div., $100 \mathrm{~ms} / \mathrm{div}$.).

It has been shown that simulations discovers relations between particular parts of conventional car during cranking. However, it is not possible to simulate several interactions including dependence of starting current versus temperature of ICE machine, EMI interference and similar. However, it could be

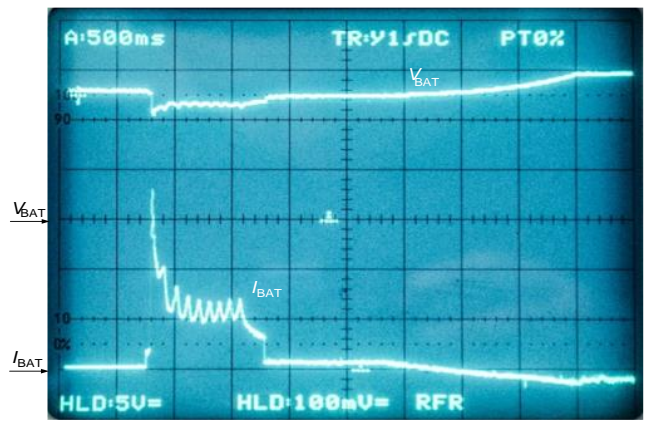

a)

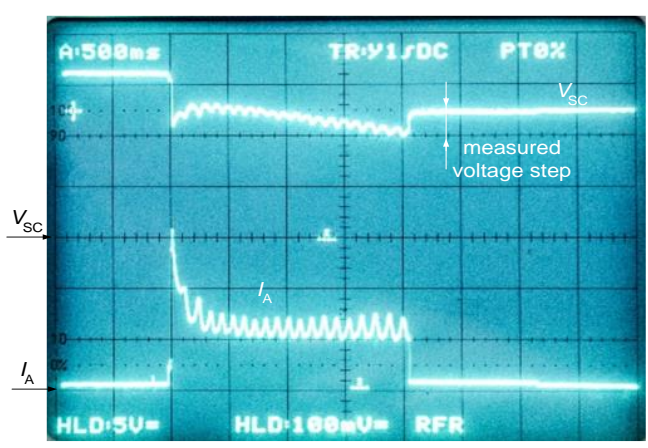

c) simulated that battery enables successful cranking for $12 \mathrm{~V}$ (Figure 5.a and Figure 6.a) but supercapacitors not because of rapid discharging and increased voltage drop during cranking (Figure 5.b and Figure 6.c).

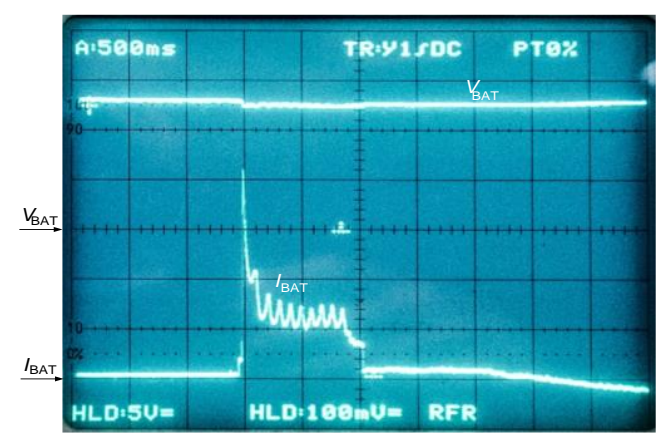

b)

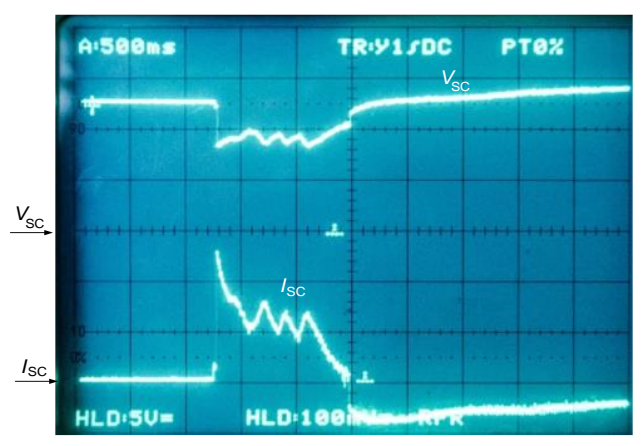

d)

Figure 6. Measured waveforms of DC bus voltage and current of the energy storage system during cranking; a) lead-acid battery cranking, b)lead-acid battery with Li-ion battery and electrolytic capacitor cranking, c) supercapacitors unsuccessful cranking, d) successful cranking with supercapacitors (100 A/div., 5 V/div., $500 \mathrm{~ms} / d i v$.$) .$ 
This situation could be changed by increase of supercapacitor capacity. Capacitance adaptation in simulation model is simple to implement, however practical observation were conducted for one capacitance value of series supercapacitors giving total capacitance of $C=66.7 \mathrm{~F}$, which equals to serial connection of six capacitors $\left(C_{\mathrm{SC}}=400 \mathrm{~F}, 2.7 \mathrm{~V}\right.$, producer: PowerStore). Since simulations allow different values of the capacitance, a border between successful and unsuccessful cranking could be precisely defined and simulated.

It could be noted that experimental measurements confirm the simulation results (Figure 6). However, it appears that simulations are much more flexible and open the wide variety of adjustments. It has been chosen that cranking lasts for 0.7 seconds and different ESS were tested under the same conditions. Such precise adjustment of testing conditions can be hardly achieved during experimental measurements. For example, temperature had not been taken into the consideration in simulated model, however a warmer ICE engine demands less quantity of energy for cranking than engine at outdoor temperature which means after the few minutes of operation ICE engine has approximately a 100 amps $(25 \%)$ lower current peak during the startup. Furthermore, torque of ICE engine is not constant and vibrations appears during the experimental tests. EMI interference of the DC machine (starter) is another example of nonlinearity which has not been precisely modeled. Experimental measurement differs from simulation in many details however current and DC voltage waveforms for successful and unsuccessful cranking are practically unchanged during all tests and simulations. Furthermore, it has been simulated that cranking with $12 \mathrm{~V}, 20 \mathrm{~F}$ charged supercapacitors is unsuccessful with $0.7 \mathrm{~s}$ or $0.9 \mathrm{~s}$ cranking interval, however capacitance increase to $60 \mathrm{~F}$ or more results in successful cranking. In this way a simulations came as a powerful tool in order to improve cranking or energy storage system performances.

\section{Observations and discussion}

Conventional car enables replacement of $12 \mathrm{~V}$ Lead-acid battery. Its mass is around $10 \mathrm{~kg}$ and volume approximately 3 liters; so many other ESS could be used instead of Lead-acid battery. Even a combinations including original lead-acid battery are possible. Lead-acid battery represents a referent case, adding of another storage systems reduces the voltage drop (Figure 6.b), equally during charging and during the discharging of storage system.
However, this approach is not cost effective but it could prolong the life time of the whole system. Independent cranking with solely Li-ion or $\mathrm{NiMH}$ batteries was not achieved because a low cost, batteries with low power density with size close to AA batteries were used (four series Li-ion $3.7 \mathrm{~V}$; $9.62 \mathrm{Wh} ; 2.6 \mathrm{Ah}$ or twelve series NiMH $1.2 \mathrm{~V}$, $600 \mathrm{mAh}$ ). On the other hand supercapacitors could be used alone (Figure 6.d) which represents durable and light solution which is desirable for the automotive applications. However, it seems that supercapacitors have larger internal resistance, compared with the lead-acid batteries but real disadvantage is their low nominal voltage (typically $2.7 \mathrm{~V}$ ) which means large number of supercapacitors has to be connected serially. In spite of these problem supercapacitors enables a successful cranking. Unsuccessful cranking demands backup power source. Besides, supercapacitors are less cost effective since six supercapacitors supplied for $95 \mathrm{EUR}$, and $55 \mathrm{Ah}$ lead acid battery could be supplied for 65 EUR.

Numerous cranking tests $(>100)$ had negative influence on battery which performance was decayed. Interval needed for achieving desired ICE engine speed of 190 rpms for startup was increased.

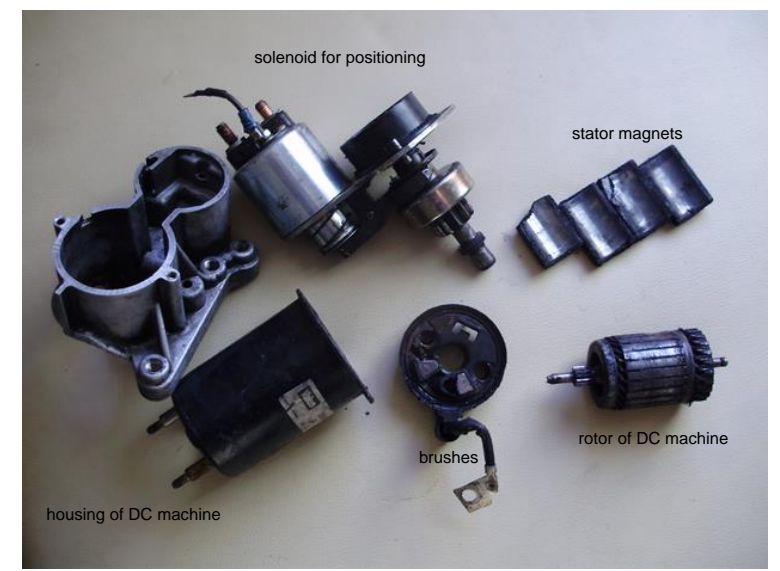

Figure 7. DC machine after disassembly; after the numerous cranking tests stator field magnets were displaced and rotor was damaged, brushes were practically vanished as a consequence of extensive use.

However, in such complex nonlinear system there are many components which could have similar effect on cranking. Decaying of battery performance was accompanied with decaying of DC machine 
performance (starter). Finally, stator magnets were displaced causing the irreversible damage on rotor windings (Figure 7.). Reliability of this system could be improved by using brushless or reluctance machines [22], [23]. In this way a single machine could be used instead of DC and AC machine from Figure 4. Furthermore, a low coast microcontroller [24] could be used for active control of switch $S_{3}$. In this manner supercapacitor can be used only during the cranking eliminating self-discharge which could discharge supercapacitor during few hours.

\section{Conclusion}

In this paper a simplified model of conventional car during cranking was developed. ICE engine was simulated by thyristor switch circuit where a thyristor gating simulate cranking of the car followed by uniform operation. Simulations for the different storage systems involving lead-acid battery and supercapacitors were considered, also. Lead-acid battery is robust storage proven by decades of successful applications. Supercapacitors could replace lead-acid batteries in conducted tests. However, lead-acid battery cranking is more reliable because, multiple attempts could be conducted. In other hand, lead-acid batteries are much heavier than supercapacitors which means a parallel connection of lead-acid battery with supercapacitor should be considered for the mass production in automobile industry. In this case a mass reduction of energy storage system (approximately of 50\%) could be expected with cycle life prolongation. During such replacement (modification) of storage system no degradation of cranking capabilities (e.g. decreased cranking current) could be expected. Furthermore, simulation model discovers more aspects of interaction compared to practical measurement which has limitations in sense of measurement equipment, and limited accessibility of particular components on commercial car.

\section{References}

[1] Opiyo, N.: Energy storage systems for PV-based communal grids, Journal of Energy Storage, vol. 7 (2016), 1-12.

[2] Budde-Meiwes, H, Drillkens, J., Lunz, B., Muennix, J., Rothgang, S., Kowal, J., Uwe Sauer, D. U.: A review of current automotive battery technology and future prospects, SAGE
Journals, Journal of Automobile Engineering, 2013.

[3] Blecua, M., Fatas, E., Ocon, P., Valenciano, J., de la Fuente, F. Trinidad: Influences of carbon materials and lignosulfonates in the negative active material of lead-acid batteries for microhybrid vehicles, Journal of Energy Storage, vol.11, (2017), 55-63.

[4] Trinidad, F., Saez, F., Valenciano, J.: High Power Valve Regulated Lead-acid Batteries for new Vehicle Requirements, Journal of power sources, vol. 95 (2001), 24-37.

[5] Cooper, A., Moseley, P.: Advanced Lead-Acid Batteries-the Way forward for Low-Cost Micro and Mild Hybrid Vehicles, World Electric Journal, vol. 3 (2009).

[6] Ikeda, H., Minami, S., Hou, S. J., Onishi, Y., Kozawa, A.: Nobel High Current Pulse Charging Method for Prolongation of Lead-acid Batteries, Journal of Asian Electric Vehicles, vol. 3, no. 1 (2005).

[7] Gidwani, M., Bhagwani, A., Rohra, N.: Supercapacitors: the near Future of Batteries, International Journal of Engineering Inventions, vol. 4 (2014), Issue 5, 22-2.

[8] Mallika, S., Kumar, R. S.: Review on Ultracapacitor - Battery Interface for Energy Management System, International Journal of Engineering and Technology, vol.3 (2011) 1, 37-43.

[9] Beguin, F., Frackowiak, E.: Supercapacitors, Materials, Systems and Applications, WileyVCH Verlag GmbH \& Co. KGaA, 2013.

[10] Chen T., Dai, L.: Carbon nanomaterials for high performance supercapacitors, Materials Today, Elsevier, vol. 16 (2013) no. 7/8.

[11] Bentley, P., Stone, D. A.: The parallel combination of a valve regulated lead acid cell and supercapacitor for use as a hybrid vehicle peak power buffer, IEEE European Conference onPower Electronics and Applications, Dresden, EPE 2005.

[12] Smith, T.A., Mars, J. P., Turner, G. A.: Using Supercapacitors to Improve Battery Performance, IEEE Power Electronics Specialists Conference, 2002.

[13] Lahyani, A., Venet, P., Guermazi, A., Troudi, A.: Utilization of Supercapacitors to Reduce Lead Acid Battery Stresses in UPS, 2012 First International Conference on Renewable Energies and Vehicular Technology, 2012.

[14] H. Liu, Z. Wang, J. Cheng and D. Maly, Improvement on the Cold Cranking Capacity of 
Commercial Vehicle by Using Supercapacitor and Lead-Acid Battery Hybrid, in IEEE Transactions on Vehicular Technology, vol. 58, (2009) no. 3, 1097-1105.

[15] K. Kroics: System for start of internal combustion engine with hybrid batterysupercapacitor source, in 2015 56th International Scientific Conference on Power and Electrical Engineering of Riga Technical University (RTUCON), 2015, 1-6.

[16] Ding, Y., Zanardelli, S., Skalny, D., Toomey, L.: Techical Challenges for Vehicle 14V/28V Lithium Ion Battery Replacement, SAE International 2011.

[17] Liu, W.: Introduction to Hybrid Vehicle System Modeling and Control, Wiley, 2013.

[18] Musolino, V., Tironi, E.: A Comparision of Supercapacitor and High-Power Lithium Batteries, IEEE, Electrical Systems for Aircraft, Railway and Ship Propulsion (ESARS), 2010

[19] Wei, T., Jia, D.: Characteristics and Design Method of Supercapacitor Modules with Voltage Equalization Circuit, IEEE $9^{\text {th }}$ Conference on Industrial Electronics and Applications (ICIEA), 2014.
[20] Culcua, H, Verbruggeb, B., Omara, N. Van Den Bosscheb, P., Van Mierloa, J.: Internal resistance of cells of lithium battery modules with FreedomCAR model, EVS24, Stavanger, Norway, May 13-16; World Electric Vehicle Journal, vol. 32009.

[21] Costa, G. G. G., Pietronero, R. C., Catunda, T.: The internal resistance of supercapacitors, July 2012. ICPE 2011, Training Physics Teachers and Educational Networks, 15-19 August 2011, Mexico City, Latin American Journal of Physics Education, vol. 6 (2012).

[22] Li, Q., Liao, S.: Design of a Distributed Switched Reluctance Motor for a Tip-Driven Fan, Engineering Review, vol. 37 (2017) issue 3, 243-256, 2017.

[23] Samani, O., N., Ganji, B.: Design Optimization of Switched Reluctance Motor for Noise Reduction, Engineering Review, vol. 36 (2016), issue 3, 293-301.

[24] Köse, E., Mühürcü, A.: Realization of a digital chaotic oscillator by using a low cost microcontroller, Engineering Review, vol. 37 (2017), issue 3, 341-348. 